\title{
Public feedback - but personal feedforward?
}

\author{
John Cowan \\ Edinburgh Napier University, UK
}

\section{Yi-Ching Jean Chiu}

Wenzao Ursuline College of Languages, Taiwan

\begin{abstract}
Academic feedback is taken here as the reporting to student writers of the strengths and weaknesses of their submitted draft work, while academic feedforward refers to constructive advice regarding possible strengthening of students' next work. Both originate from a tutor's initial judgement of a student's work. Feedback and feedforward on work showing need for improvement are problematic in a Confucian Heritage Culture. Even gently constructive advice within a programme seeking evidence for assessment of critical thinking may lead to perception of hurtful criticism by Taiwanese students. Some could withdraw from class activity accordingly. So the writers adjusted their response style. They now choose between different approaches featuring tutorial feedback or feedforward, depending on the standard of work being judged. When individual postings feature poor critical thinking, the writers opt for private messages concentrating on constructive feedforward. For better postings, they provide positive feedback with reasons for their judgements, and summarise to the class these exemplars of generic strengths in critical thinking. They also offer private prompting when they see scope for further enrichment of an able student's critical thinking. This might also be a useful practice when tutoring solely in the West.
\end{abstract}

Keywords: Confucian Heritage Culture; public feedback; private feedforward; assessment. 


\section{Definitions of key terms}

Academic feedback is taken here to be the reporting to a student writer of the strengths and weaknesses of their submitted or draft work. Academic feedforward is taken as the provision of constructive advice about possible strengthening of a student's next submitted work. Both originate from the tutor's initial and judgemental consideration of a student's work. They are radically different in purpose and content. Feedback is an expanded judgement of completed work. Feedforward is a detailed suggestion about how to tackle the next piece of work more effectively than the present one.

\section{Introduction}

Much traditional teaching has deliberately followed a 'rule-eg-rule' sequence, where examples are sandwiched between rules (Bligh, 1998). Skemp (1971, p.32) pointed out that new topics are thus often introduced by descriptions 'of the most admirable brevity and exactitude for the teacher (who already has the concepts to which they refer) but [which are] unintelligible to the student'. Accordingly he advocated that:

Concepts of a higher order than those which a person already has cannot be communicated to him [sic] by a definition, but only by arranging for him to encounter a suitable collection of examples. (Skemp, 1971, p.32)

The importance of starting learning from consideration of pertinent examples (Cowan, 2006) was the subject of research by Skemp (1971) and Sadler (1989). They concluded that understanding a meaning or concept begins from an opportunity to discern meaning by perceiving the similarities between positive examples. Thereafter understanding may be further developed reflectively. The same principle, including the importance of later using non-examples (Skemp, 1971), has been re-iterated by others (Markle, 1978; Brookfield, 1990). A non-example in this context is something which might seem to be an example, yet lies outwith the border-line of the defined class; and so consideration of it can clarify the characteristics of the class. Skemp illustrates this by using non-examples such as settees and stools to clarify the concept of chair. 
When feedback and feedforward focus on examples produced by the learners themselves, and with which they will already be familiar, they can better understand the generic strengths and weaknesses of the examples. Thus their own examples can be an effective way to help students identify strengths and areas for improvement.

Nevertheless, in a Confucian Heritage Culture ( $\mathrm{CHC}$ ) background, where social harmony is highly revered, publicising critical feedback and feedforward based on weak examples written by students can be problematic and socially disruptive, even if potentially beneficial. The loss of face can be hurtful, and students may even withdraw from further activities accordingly.

Therefore the purpose of this action-research study was to devise and validate culturally acceptable means of more effectively communicating feedback and feedforward to $\mathrm{CHC}$ learners, using their own discussion board postings as examples. This enquiry was located within the wider context of Chiu's funded research into education for critical thinking, which will be reported elsewhere in due course. The impact of the initiatives in the present enquiry has been judged by the quality of the critical thinking postings and interactions on the discussion boards, and by student evaluation of the facilitative support they received.

\section{Literature relevant to the writers' practices}

Nurturing critical thinking skills has proved challenging for European facilitators (Astleitner, 2002). They have found it difficult to teach their learners to 'transform source texts into well-reasoned claims that address a specific issue' (Higgins, 1993). Many students are unaccustomed to being objective, cannot generate counter-arguments (Stein and Bernas, 1999), and progress with difficulty from personal opinions to evidence-based judgements (Brem and Rips, 2000). They do not easily move from dualist to relativist epistemologies (Perry, 1970), or to considering, questioning and evaluating possible options.

Chiu (2006; 2007; 2009) had found these problems in Taiwan and has summarised additional difficulties for those teaching critical thinking in a $\mathrm{CHC}$ context. $\mathrm{CHC}$ students are reluctant to declare contrary views or to disagree directly in public (Carless, 2007). This reticence inhibits communications with peers (other than close friends), with teachers, and with published works. CHC students readily identify grounds for reasoned 
disagreement. However, in most settings and more so than their Western counterparts, they find it awkward to express that disagreement.

Their inhibitions can be lessened through the exercise of face-to-face 'shepherd leadership' (Chiu, 2009). Hence Chiu follows McCormick and Davenport's (2004) model (Chiu, 2009), and mainly does so face-to-face. This shepherd leader/teacher knows every learner personally through affective personal relationships within the Chinese educational context (Chiu, 2009). She promotes socio-constructivist interactions, helping active learners to overcome cultural barriers to posting online (Merryfield, 2003). She models thinking cognitively, as did Yu and Chou (2004). She encourages emerging student leaders to assist slower fellow learners, or when students communicate asynchronously online (Kao and Chen, 2003; Wang and Woo, 2007). The online discussions in her course complement face-to-face tutoring by allowing participants time to consider and carefully articulate their responses to tutors and to each other (Kao and Chen, 2003). With 'the security veil' over their online interactions (Merryfield, 2003), it is easier to disagree with someone whom they need not meet face-to-face.

Cowan has long followed Rogerian principles (Rogers, 1980; 1983) of affective support, enabling learners from different backgrounds to confidently acquire learning and to develop abilities. He establishes congruence or frankness in his early and authentic relationships with learners (Brookfield, 1990, p.164). He exhibits unconditional positive regard for cross-cultural differences and he shows empathy by developing 'personcentred' arrangements in online discussions, to offer freedom to learn throughout this study.

\section{Methodology and methods}

\section{Setting and participants}

Chiu is responsible for an EFL course in the only foreign language college in Taiwan. A major socio-cognitive course aim is the development of critical thinking. In 2009, she recruited Cowan to voluntarily provide an interactive Western input online. His rationale and approach was to be complementary to Chiu's.

During the period 2008-12, approximately 35 junior-English major students have participated each year in online discussions. Their English proficiency has varied from 
higher-intermediate to lower-intermediate. During their two-semester programme, the students each week have attended a one-hour formal session led by Chiu. This was followed by a class hour devoted to various planned events, leading into asynchronous online discussions. These featured controversial themes taken from diverse films, associated with recommended readings and materials obtained through students' online searching. The combination of themes and activities was devised by Chiu (2009), in accordance with the principles of critical thinking (Erwing, 2000).

\section{Design}

Academic year 2009-10 was an induction experience for Cowan. He had been briefed by reading Chiu's papers and by collaboration with her in writing a book chapter on the importance of affective support for learners (Chiu and Cowan, 2009). At first he responded directly on the discussion board to each student's postings. He was supported in this by Chiu's face-to-face formal and informal interactions in class. His cautiously worded feedback on individual postings nonetheless generated mixed class reactions, ranging from claims of reading overload, to embarrassment or hurt occasioned by reservations expressed or perceived in Cowan's public responses. On Chiu's advice, he moved in academic year 2010-11 to posting anonymised and general responses to sets of 10-15 student postings. Student complaints evaporated, but the teachers saw little discernible impact from this option on the quality of the student postings, judged against the characteristics of sound critical thinking.

In 2010-11, Cowan began to concentrate facilitatively on a selection of cost-effectively brief, direct, personal e-mail messages. Where a student had made a sound discussion posting with little need or scope for feedforward, he simply provided reasoned feedback on the merits of that posting. Where a posting was weak, he explained what was needed to bring about improvement and offered suitable feedforward. In both approaches, he 'nudged' students forward (Bruner, 1986) towards their Zones of Proximal Development (Vygotsky, 1978). 


\section{Emergent rationale and methodology}

Cowan and Chiu decided that, in 2011-12, the effective early teaching of critical thinking skills should be centred upon examples, which they predicted would be especially useful if drawn from a student's own postings. Where these examples are basically sound, facilitative comments should concentrate on providing feedback, commending the posting and explaining in what ways it is commendable; some such examples and their merits would be publicised to the class. Where the posting from which examples can be drawn is weak, facilitative comments should concentrate on constructive feedforward, accompanied by the reasons for following it. This feedforward should be private to avoid embarrassment to the student author.

\section{Methods of evaluation}

Critical thinking pre-tests and post-tests were carried out each year and reported as part of the main project. They had already quantitatively shown tangible development on this project of students' critical thinking abilities and attitudes (Chiu, 2006; 2007; 2009). The hope of achieving further improvement in the quality of discussion board postings, through working on the effectiveness of the facilitation, called for a qualitative approach to evaluation. The writers opted for an illuminative approach (Parlett and Hamilton, 1972). The basic principle is for the investigator to associate with the participants (students, teachers, etc.) sufficiently to pick up how they think and feel about the situation, and detecting in an open-ended way what issues are important, avoiding asking the wrong questions or measuring the wrong things. Cowan attempted to do this.

To illuminatively evaluate the facilitation, the study first utilised a semi-structured questionnaire. This asked students whether the Western online facilitation helped their critical thinking and, if so, how. Then two focus groups were conducted - one with active students who had interacted with Cowan, and one with a mixed group of active learners and infrequent contributors. Next, Cowan invited direct formative advice by e-mail, from students who had already volunteered their feedback to him on the nature of their experience. Finally the postings in the second discussion of 2011-12 were analysed in terms of interaction and critical thinking content, and compared with a similar discussion in 2010-11. 


\section{Analysis of results}

\section{Postings}

The postings in academic year 2011-12 were of a different character to those of the two previous years. The following table illustrates key results.

Table 1. Key statistics on comparative postings.

\begin{tabular}{|c|c|c|c|}
\hline Analysis Items & $\begin{array}{l}2010-11 \\
\text { Forum } 1\end{array}$ & $\begin{array}{l}\text { 2011-12 } \\
\text { Forum } 1\end{array}$ & $\begin{array}{l}\text { 2011-12 } \\
\text { Forum } 2\end{array}$ \\
\hline Total number of students & 32 & 34 & 34 \\
\hline Total number of student postings & 88 & 200 & 144 \\
\hline $\begin{array}{l}\text { Number of postings with insufficient inclusion of } \\
\text { reasoning, examples or analysis }\end{array}$ & 23 & 14 & 7 \\
\hline $\begin{array}{l}\text { Number of postings with minimal yet adequate } \\
\text { reasoning, evidence or analysis - often echoing } \\
\text { previous postings }\end{array}$ & 55 & 41 & 26 \\
\hline $\begin{array}{l}\text { Number of postings making pertinent reference to } \\
\text { content of a first posting by another, without simply } \\
\text { repeating it }\end{array}$ & 2 & 13 & 10 \\
\hline $\begin{array}{l}\text { Number of postings responding significantly to } \\
\text { content of a first posting by another }\end{array}$ & 7 & 54 & 55 \\
\hline $\begin{array}{l}\text { Number of postings responding to a first posting by } \\
\text { another, with reasoned agreement or disagreement, } \\
\text { or by posing a pertinent question }\end{array}$ & 1 & 62 & 41 \\
\hline Number of postings reporting a change of opinion & 0 & 16 & 5 \\
\hline $\begin{array}{l}\text { Included in the above, the number of sustained } \\
\text { exchanges in which B comments on A's posting, } \\
\text { and } A \text { responds, with at least one such } A / B / A \\
\text { exchange, though some were } A / B / A / B / A\end{array}$ & 0 & 49 & 15 \\
\hline Total number of staff postings & 11 & 21 & 15 \\
\hline
\end{tabular}


In 2009-11:

- Most postings were isolated answers to the initial questions or prompts declared by Chiu. Most were bland, superficial, and shared common content without showing evidence of direct plagiarism.

- Reasoned presentation of evidence or of relevant personal experience was rare.

- There were very few postings in which the writer referred to or supplemented a previous posting, and disagreements between students were even more rare.

- Dialogue, in which $B$ responded to $A$, and A commented further, did not occur.

In the opening discussions of 2011-12, in contrast:

- Most postings presented significant and clearly individual statements of viewpoints, supported by examples, citations from sources or personal experience.

- Disagreements were not uncommon. They were usually presented in a courteous format in which the second writers first stated politely the aspects of the first posting with which they had agreed. They then frankly declared, explained and justified their disagreement. They might also sustain the discussion by posing a valid and searching question for the first writer (and others) to consider.

- Students readily responded to facilitative e-mail suggestions from Cowan regarding ways in which they might extend their contribution to the class discussion.

\section{Features of the student experience}

Four strong themes emerged from the questionnaire, focus groups and informal feedback and formative advice. Each was endorsed by more than $50 \%$ of the respondents. These themes were as follows, partly explained in typical and un-edited responses from student questionnaires or focus group reports:

1. The personal and private nature of the facilitative contact:

He replied to every student's opinions one by one, which let us know directly the good part of our answer and the weak part which can improve. 
2. The absence of hurtful criticism in the facilitation, and its emphasis on encouragement:

The first reason is that he encourages us in every posting we made, no matter it was a good or poor one. That's very important! Because without encouragement, we will lose our confidence and not like to post any new things any more. Second, he tells us what we should further take insight rather than just agree what has been mentioned over and over again. From his emails, which are in a very friendly tone, we can learn a lot about critical thinking skills.

3. The development of questioning, seeking and examining reasons:

I didn't have the habit of questioning and challenging any statements I read. Now I will hesitate to easily agree with others' statements. I will question them first.

4. Looking for, comparing and weighing up several viewpoints:

I used to view an issue from the surface level, but this semester I start to reason an issue from different aspects. I have learned to consider the aspects that I have never had thought about before, like the third option in the economy-environment struggle. In my opinion, the most important and precious thing we learned on this online forum is not learning how to outstrip our rivals but learning how to think logically and organize our ideas well.

\section{Discussion}

The quality of student postings and discussion changed completely in character. The only tutorial or other changes were as described above, under 'emergent rationale and methodology'. It seems reasonable to presume causation.

The willingness of some students to express disagreement with peers, even after first offering a courteous statement of points agreed upon, is at variance with the experience of Chiu and the witness of Eastern literature regarding $\mathrm{CHC}$ students' reluctance to disagree publicly, except with close friends. This suggests, but does not prove, the effectiveness of 
the combined Western and Eastern approaches in establishing for students a feeling of partaking safely in a supportive community of enquiry.

The cost-effectiveness of Cowan's activities naturally causes for concern. His support hours have been projected over a full academic year, on the basis of the steadily diminishing provision called for and provided during academic years 2009-11. The result still leaves the writers to wrestle with a level of student support approximating to twice the UK norm. Cowan points to his work with Francis (Francis and Cowan, 2008) in promoting facilitative peer interaction. This would appear to be the way ahead, both for reasons of cost-effectiveness and to exploit the potential of peer-facilitation and interaction.

\section{Conclusion}

In an Eastern context, the writers have responded to cultural factors in developing a combined facilitative style for discussion board activity. Consequently they have differentiated in their handling of strong and weak postings by students, using two distinct channels and emphases for public feedback and private feedforward. The outcomes have been encouraging. Although this pilot study took place in a particular setting in which $\mathrm{CHC}$ sensitivities were particularly relevant, there seem grounds for considering that the findings might also apply in less sensitive situations, where student reactions to feedback and feedforward are not studied or compared. Might this distinction and use of two channels of communication for feedback and feedforward be equally appropriate for Western practice?

The Western component of the joint facilitation of the development of critical thinking set out to continue Cowan's commitment to embodying congruence, empathy and unconditional positive regard in his interactions with students. Readers are invited to inform their own judgement of the impact of that transfer of Western practice by considering a supportive and volunteered message which he received after concluding his commitment to the project, in November 2011:

In my opinion, the most important and precious thing we learned on this online forum is not learning how to outstrip our rivals but learning how to think logically and organize our ideas well. Moreover, I think your comments played a big role as well. They made me think it's worth to spend so much time on those numerous postings. 
What's more, all of the comments you gave are so useful, practical and inspiring. Sometimes you gave me suggestions when I didn't do a good job, yet those words didn't hurt my feeling at all because I know they came out of you sincerely. You want to help us and make our skills of critical thinking better! That's why I do appreciate for what you've done. (Chou Youn-Shin, 2011)

\section{References}

Astleitner, H. (2002) 'Teaching critical thinking online', Journal of Instructional Psychology, 29(2), pp. 53-76.

Bligh, D.A. (1998) What's the use of lectures? Bristol: Intellect.

Brem, S.H. and Rips, L.J. (2000) 'Explanation and evidence in informed argument', Cognitive Science, 24(4), pp. 573-604.

Brookfield, S.D. (1990) The skilful teacher. San Francisco: Jossey-Bass.

Bruner, J. (1986) Actual minds, possible worlds. Cambridge, MA: Harvard University Press.

Carless, D. (2007) 'The suitability of task-based approaches for secondary schools: perspectives from Hong Kong', System, 35(4), pp. 595-608.

Chiu, Y.C. (2006) Exploring student and teacher interactions for critical thinking in face-toface and online environments in an EFL course in Taiwan. Unpublished Doctoral thesis, Australian Catholic University, Melbourne.

Chiu, Y.C. (2007) 'Using the Shepherd Metaphor in Crossing Cultural Boundary Online for CHC Students', Proceedings of the 2007 E-Learning IADIS Conference, International Association for the Development of the Information Society. Lisbon, Portugal 6-8 July.

Chiu, Y.C. (2009) 'Facilitating Asian students' critical thinking in online discussions', British Journal of Educational Technology, 40(1), pp. 42-57. 
Chiu, Y.C. and Cowan, J. (2009) 'Dealing with affective needs in e-learning: contrasting two cases in two cultures', in Olaniran, B. (ed.) Cases on successful e-learning practices in the developed and developing world: methods for the global information economy. Hershey, New York: IGI Global publications, pp. 42-57.

Chou Youn-Shin (2011) Personal communication to Cowan.

Cowan, J. (2006) On becoming an innovative university teacher. 2nd edn. Maidenhead, UK: Open University Press.

Erwing, T.D. (2000) National postsecondary education cooperative sourcebook on assessment, Vol.1: definitions and assessment methods for critical thinking, problem-solving and writing (No. NPEC2000195).

Francis, H.F. and Cowan, J. (2008) 'Fostering an action-research dynamic amongst student practitioners', Journal of European Industrial Training, 32(5), pp. 336-346.

Higgins, L. (1993) 'Reading to argue: helping students transform source texts', in Penrose, A. and Sitko, B. (eds.) Hearing ourselves think: cognitive research in the college writing classroom. New York: Oxford University Press, pp. 70-101.

Kao, T.C. and Chen, Y.F. (2003) 'Group dynamics interactive skills in asynchronous small group discussion online', International Conference of Distance Education. National Taiwan University, Taipei, Taiwan 10-11 December.

Markle, S.M. (1978) 'Teaching conceptual networks', NSPI Journal, 17(1), pp. 4-7.

McCormick, B. and Davenport, D. (2004) Shepherd leadership: wisdom for leaders from Psalm 23 (Y. C. Geh, Trans.). Taipei: Apocalypse Press.

Merryfield, M. (2003) Like a veil: cross-cultural experiential learning online. Available at: http://citejournal.org/vol3/iss2/socialstudies/article1.cfm (Accessed: 30 March 2012).

Parlett, M. and Hamilton, D. (1972) Evaluation as illumination. Occasional Paper, University of Edinburgh. Centre for Research in the Educational Sciences. 
Perry, W.G. (1970) Forms of intellectual and ethical development in the college years. New York: Holt, Rinehart and Winston.

Rogers, C.R. (1980) A way of being. Boston: Houghton Mifflin.

Rogers, C.R. (1983) Freedom to learn - for the 80's. Columbus, Ohio: Charles E Merrill.

Sadler, D. (1989) 'Formative assessment and the design of instructional systems', Instructional Science, 18(2), pp.119-144.

Skemp, R. (1971) The psychology of teaching mathematics. London: Penguin.

Stein, N.L. and Bernas, R. (1999), The early emergence of argumentative knowledge and skill', in Andriessen, J. and Corrier, P. (eds.) Foundations of argumentative text processing. Amsterdam, Amsterdam University Press, pp. 97-116.

Vygotsky, L.S. (1978) Mind in society. Cambridge, MA: Harvard University Press.

Wang, Q. and Woo, H.L. (2007) 'Comparing asynchronous online discussions and face-toface discussions in a classroom setting', British Journal of Educational Technology, 38(2), pp. 272-286.

Yu, Y.L. and Chou, S.G. (2004) 'Integrating writing with reading in EFL writing classroom with metacognitive approach', Selected papers from Thirteenth International Symposium and Book Fair on English Teaching, 1, pp. 708-71.

\section{Author details}

John Cowan is Professor Emeritus of Learning Development of the Open University. Nowadays he is a part-time tutor on a range of face-to-face and distance learning courses, with a special interest in personal and professional development, and in self-assessment and formative assessment. 
Dr. Yi Ching Jean Chiu is Associate Professor of English Department, Wenzao Ursuline College of Languages, Taiwan. She has been involved in research pertinent to critical thinking in online discussions, and cross-cultural communications between Chinese English learners and Westerners. 